\title{
ENSINAR LÍNGUA PORTUGUESA EM TEMPOS DE TECNOLOGIA DIGITAL: ENTRE A OUSADIA E O DESAFIO.
}

\author{
Teaching Portuguese Language in times of digital technology: \\ Between daring and challenging
}

Chirley DOMINGUES

Universidade do Sul de Santa Catarina chirley.domingues@yahoo.com https://orcid.org/0000-0002-7416-0977

Silvia Maria CANTELI Universidade Federal de Santa Catarina silviacanteli.s@gmail.com https://orcid.org/0000-0003-3640-2258

RESUMO: O relato de experiência apresentado resulta de uma prática de estágio curricular obrigatório realizada por alunos da Universidade Federal de Santa Catarina em uma escola pública de Florianópolis, capital do estado. A prática aqui analisada foi desenvolvida com uma turma do ensino médio noturno e teve como ponto de partida um projeto de docência que contemplou os eixos organizadores do ensino de língua, leitura-escrita, fala-escuta e, sobretudo, análise linguística, aliados ao uso da tecnologia. Analisar aquele contexto de formação docente, considerando a atuação dos futuros professores e a prática pedagógica realizada, a partir de discussões apresentadas por Antunes (2003), Rojo (2009), Geraldi (2010) e Santaella (2013) é o que esse estudo propõe. A experiência mostrou que está em curso um novo desafio para a escola e para os professores, elaborar estratégias de integração entre os processos educativos anteriores e o acesso aos mecanismos de aprendizagem resultantes da inserção dos usuários nos espaços da cibercultura. PALAVRAS-CHAVE: Ensino e Tecnologia; Figuras de Linguagem; Ensino de Língua Portuguesa.

ABSTRACT: This experience report results from a mandatory curricular practicum carried out by students from the Federal University of Santa Catarina in a public school in Florianópolis, capital of the state. The practicum analyzed here was developed with a night high school class and had as its starting point a teaching project that covered the organizing axes of language teaching, reading-writing, spe-

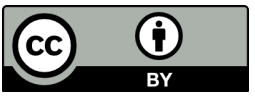


aking-listening and, above all, linguistic analysis, allied to the use of technology.[C1] This study proposes to analyze that context of teacher education, considering the role of prospective teachers and the pedagogical practice carried out, based on discussions presented by Antunes (2003), Rojo (2009), Geraldi (2010) and Santaella (2013). The experience showed that schools and teachers are facing an ongoing challenge, to elaborate integration strategies between the previous educational processes and the access to the learning mechanisms resulting from the insertion of users in cyberculture spaces. KEYWORDS: Teaching and Technology. Figures of Speech. Portuguese Language Teaching.

\section{INTRODUÇÃO}

Este relato de experiência resulta do desenvolvimento, e posterior análise, de uma prática docente realizada por estagiários do Curso de Letras da Universidade Federal de Santa Catarina - UFSC, em uma escola pública de Florianópolis. As etapas dessa prática constituíram quatro momentos essenciais: i) observação de aulas na educação básica; ii) elaboração de um projeto de docência; iii) aulas ministradas em uma turma do ensino médio $^{1}$; iv) elaboração do relatório de estágio. Para refletir sobre a atuação dos futuros licenciados e sobre o contexto de ensino em que ela se realizou, nos ${ }^{2}$ dedicamos à leitura e análise dos registros ${ }^{3}$ dessa prática docente, documentos que subsidiaram nosso olhar sobre aquele espaço real de docência.

As atividades didático-pedagógicas realizadas envolveram 43 alunos, com faixa etária de 15 a 24 anos, de uma turma do $1^{\circ}$ Ano do ensino médio noturno, denominada Turma 131. Como é comum em muitas instituições de educação no nosso país, naquele contexto de ensino encontramos alunos que enfrentam inúmeros desafios para concluir a Educação Básica, como a inserção precoce no mercado de trabalho, empurrados pela necessidade de complementar a renda familiar, o pouco interesse no acesso ao ensino superior e algumas lacunas na formação, que, ao que tudo indica, resultam das etapas

\footnotetext{
${ }^{1} \mathrm{O}$ projeto de docência aqui analisado contemplou $20 \mathrm{~h} / \mathrm{a}$. Para a atividade desenvolvida foram dedicadas $10 \mathrm{~h} / \mathrm{a}$. A necessidade de usar essa carga-horária deve-se ao fato de o curso noturno contemplar apenas 38 minutos de aula, o que exige dos professores um certo rigor no controle do tempo dedicados às atividades.

${ }^{2} \mathrm{O}$ estudo foi realizado pela supervisora do estágio, naquele momento atuando como professora da Universidade Federal de Santa Catarina.

${ }^{3}$ Os documentos aos quais nos referimos são: Relatório de Estágio, no qual constam os registros e a análise dos estagiários sobre todo o processo de realização da prática docente; Fichas de Avaliação, onde são feitos os registros da supervisora do estágio sobre a atuação individual dos estagiários.
}

Revista X, v. 16, n. 6, p. 1908-1924, 2021. 
escolares anteriores. Tal realidade foi percebida pelos professores-estagiários durante o período de observação das aulas de Língua Portuguesa na referida instituição de ensino, etapa anterior às aulas ministradas ${ }^{4}$.

Em pouco mais de três semanas, período destinado à observação das aulas, chamou a atenção dos professores-estagiários, naquele momento no papel de observadores, a falta de interesse de parte dos alunos da Turma 131 pelos conteúdos ministrados pela professora regente. Nos registros das aulas observadas encontramos, em diversas passagens, referência à certa resistência dos jovens estudantes para se envolverem com as leituras ou atividades propostas, bem como à dificuldade para ficarem atentos às aulas e, sobretudo, não usarem os celulares em sala. Por outro lado, quando era liberado o uso dos telefones para pesquisarem alguma questão relacionada ao tema da aula, muitos se mostravam mais envolvidos. Nesses momentos, os alunos transitavam por sites de busca e pelas redes sociais com agilidade, facilidade e muita familiaridade.

A realidade encontrada levou a dois questionamentos que se tornaram recorrentes durante a elaboração do projeto de docência ${ }^{5}$ : i) como envolver aqueles jovens alunos nas aulas de Língua Portuguesa?; ii) como desenvolver uma prática pedagógica exitosa contemplando Figuras de Linguagem e Histórias em Quadrinhos, conteúdos curriculares exigido pela escola? Considerando o contexto descrito, estagiários e supervisora passaram a discutir sobre a possibilidade de elaborar um trabalho que envolvesse pesquisa, leitura e escrita, com o propósito de desenvolver a capacidade de interpretação e análise de recursos linguísticos existentes no cotidiano, promovendo a consolidação do aprendizado dos estudantes por meio da socialização e do uso da tecnologia.

A ideia para o projeto de docência foi, então, discutida e, posteriormente, apresentada à professora regente da turma. Após aprovada, foi colocada em prática, no primeiro semestre de 2019, uma proposta de docência desenvolvida a partir do desdobramento de objetivos que possibilitassem aos estudantes do Ensino Médio a: i) reconhecer o sentido conotativo presente nas expressões e figuras de linguagem em textos diversos; ii) refletir sobre os diferentes tipos de figura de linguagem e os possíveis usos que a língua pode assumir em distintos contexto e espaço; iii) desenvolver o pensamento criativo e estimular o raciocínio ao realizar, de forma criativa e espontânea, atividades de

\footnotetext{
${ }^{4} \mathrm{O}$ estágio no curso de Letras Português da UFSC contempla duas disciplinas - Estágio de Ensino de Língua Portuguesa e Literatura I e Estágio de Ensino de Língua Portuguesa e Literatura II. Nas duas disciplinas os alunos devem realizar seis etapas obrigatórias: 1. inserção no espaço escolar; 2. observação de aulas; 3. planejamento; 4. Docência; 5 . análise reflexiva da prática e 6. socialização.

${ }^{5} \mathrm{O}$ projeto de docência é elaborado pelos estagiários com a orientação da professora supervisora do estágio curricular obrigatório.
}

Revista X, v. 16, n. 6, p. 1908-1924, 2021. 
leitura, interpretação e produção de textos de gêneros diversos; iv) potencializar o uso de recursos tecnológicos em sala de aula como mediadores entre os alunos e os conteúdos obrigatórios estudados.

O percurso realizado pelos alunos da Turma 131 para a realização de uma das atividades propostas durante o estágio supervisionado, a análise desse trabalho, com o conteúdo Figuras de Linguagem, e as reflexões que suscitaram nos futuros professores envolvidos nessa experiência de docência é o que pretendemos problematizar.

\section{O DESAFIO}

Iniciamos o século XXI com uma realidade que não se pode negar, há uma nova forma de nos relacionarmos com o mundo da escrita e novos hábitos de leitura, que resultam da evolução da textualidade digital. E não precisamos sequer sair de nossas casas para nos depararmos com essa "(r)evolução". Cotidianamente, testemunhamos nossas crianças e jovens lendo e escrevendo em computadores, tablets, notebooks, smartphones, $i$-phones, iPads etc. Como sabemos, estes equipamentos possibilitam a ampla inserção no mundo virtual, no aqui e agora dos acontecimentos, na atualização instantânea dos fatos.

E se as nossas crianças e jovens estão fazendo uso dos artefatos tecnológicos com tanta agilidade e competência, elas o fazem, por certo, porque dominam a leitura e a escrita. Tal constatação nos leva a seguinte reflexão: considerando que é na escola que eles se formam, e quiçá se tornam, leitores e produtores de textos, é curioso que nesse espaço ainda haja resistência, por parte de alguns alunos, a atividades que corriqueiramente envolvem a escrita e a leitura. Diante da realidade apresentada, nos sentimos desafiados a entender o que acontece nessas práticas de contato com a língua escrita que revelam atitudes, à primeira vista, tão antagônicas.

Grande parte das discussões que versam sobre o assunto apontam, geralmente, dois problemas: a ênfase no ensino da norma culta da língua portuguesa, centrado nas normas gramaticais e em exercícios sobre a estrutura da língua, e o cerceamento sofrido pelos estudantes nos momentos de leitura e nas propostas de produção texto que, longe de se aproximarem dos usos e práticas sociais da linguagem, limitam-se, muitas vezes, à mera atividade escolar.

Publicações resultantes de pesquisas e estudos de autores como Geraldi (2010) e Rojo (2000), bem como documentos norteadores que surgiram no final do século XX, como os PCNs (1998), e início do século XXI, como as Orientações Curriculares Nacionais para o Ensino Médio (2006), já apresentavam importantes reflexões sobre as práticas de leitura e de escrita no contexto escolar brasileiro, apontando para a necessidade Revista X, v. 16, n. 6, p. 1908-1924, 2021. 
de mudanças significativas no ensino, que se ocupava, antes de tudo, dos aspectos formais da língua. Os discursos convergiam em defesa da necessária ruptura com o que ainda estava em vigência naquele momento, ou seja, um ensino marcado por práticas que priorizavam leituras dirigidas, baseadas em interpretações fechadas, direcionadas por questões disponíveis nos manuais didáticos, exercícios de correção gramatical, ou atividades de produção de textos cujo objetivo principal se resumia em verificar o uso correto da norma culta da língua. Ou seja, estratégias limitadoras, e limitadas ao âmbito dos letramentos escolares, "que permanecem arraigados em práticas cristalizadas, criando insuficiências". (ROJO, 2009, p. 23).

O que aqueles e outros autores defendiam, e por certo ainda defendem, é um ensino de língua mais significativo que proporcione um "Debruçar-se sobre a língua em funcionamento, lendo textos, debatendo temas, esquematizando intervenções, fazendo anotações, revisando conceitos e concepções" (GERALDI, 2010, p. 167). Ou seja, atividades que levem nossas crianças e jovens a ler e a escrever de modo competente e adequado, nas mais variadas situações em que a língua é requerida socialmente. Mas, para que essa meta seja alcançada é necessário, ainda, levar em conta um aspecto de suma importância, "os letramentos na sociedade atual urbana sofisticaram-se muito nos últimos vinte anos, exigindo novas competências e capacidades de tratamento dos textos e da informação" (ROJO, 2010, p. 23), que vão além do que se exige em contato com a cultura do impresso.

Há muito que as avaliações sobre a educação nacional vêm revelando indícios de que o letramento escolar, voltado para a prática de textos escolares e de gêneros escolarizados advindos de outros contextos, não estão sendo suficientes para que os alunos possam fazer uso das múltiplas linguagens com as quais se deparam fora da escola. Concordando com essa defesa, Rojo pondera a respeito da necessidade de se "ampliar e democratizar tanto as práticas e eventos de letramentos que têm lugar na escola como o universo e a natureza dos textos que nela circulam". (2009, p. 108). Para tanto, a escola precisa incorporar no seu cotidiano o que já está incorporado nos discursos institucionais, ou seja, um ensino de língua profícuo no mundo contemporâneo que inclua

a leitura e a produção de textos em diversas linguagens e semioses (verbal oral e escrita, musical, imagética [imagens estáticas e em movimentos, nas fotos, no cinema, nos vídeos, na tv], corporal e do movimento [nas danças, performances, esportes, atividades de condicionamento físico], matemática, digital etc). Assim, impõe-se trabalhar com os impressos, mas também com as mídias analógicas ( $\mathrm{TV}$, rádio, vídeos, cinema, fotografia) e, sobretudo, com as digitais, 
já que a digitalização é o futuro da informação e da comunicação. (ROJO, 2009, p. 119. Grifo nosso).

Não há como nos mantermos na lógica de um ensino que se limita à escrita linear e ao contato instrumental com a língua, em contextos habitados por um "novo sujeito contemporâneo [...] diferente daquele formado na e pela cultura impressa" que "se apresenta hoje como um interator, com papel ativo, que faz uso das linguagens hipermidiáticas." (OSWALD; FERREIRA, 2012, p. 59. Grifo nosso). A cultura digital tem gestado novos leitores e escritores "que se caracterizam pelas sensibilidades desenvolvidas na relação com os artefatos tecnológicos de seu tempo e que têm suas formas de pensar, agir e se expressar marcadas, hoje, pelas dinâmicas da cultura digital em rede". (OSWALD; FERREIRA, 2012, p. 60). A relação com o conhecimento, portanto, não pode se manter a mesma de séculos atrás.

Algumas experiências no Brasil têm mostrado que há outros caminhos. A título de ilustração, usamos como referência o grupo de pesquisadores do Programa de Pósgraduação em Educação da Universidade Federal do Rio Grande do Norte que, desde 2005, desenvolve pesquisas e reflete sobre "as relações das crianças e jovens com tecnologias que utilizam as linguagens audiovisuais e hipermidiáticas, e apontam para a constituição de novos sujeitos culturais, cujos modos de ser, de aprender, de expressar-se, de ler e de escreversugerem mudanças nas práticas educativas". (OSWALD; FERREIRA, 2012, p. 60).

Os resultados dos trabalhos desenvolvidos por esse grupo vêm mostrando que a escola pode se aproximar das práticas comunicacionais da contemporaneidade que contemplam formas mais dinâmicas de compartilhamento e socialização, que potencializam construções coletivas e facilitam a interação. De acordo com os pesquisadores, o acesso aos dispositivos móveis resultou em novas formas de uso da língua, o que os levou a concluir que "A importância da imagem e a necessidade de sintetizar as escritas apontam para textualidades construídas a partir de fragmentações, que não se atêm às normas da linguagem culta e que são exercitadas em fluxos contínuos e espontâneos". (OSWALD; FERREIRA, 2012, p. 65).

Sabemos que não há como retroceder. A familiaridade dos alunos com os modernos dispositivos móveis não deixa dúvidas de que há novos modos de lidar com o conhecimento. Assim sendo, precisamos nos aproximar de e conhecer as "práticas que fazem parte dos cotidianos de crianças e jovens, cujas mochilas recheadas de livros didáticos são contraditórias com o modo não linear de lidar com o conhecimento e a cultura, com base na ação compartilhada e interativa possibilitada pelos usos das 
mídias digitais" (OSWALD; FERREIRA, 2012, p. 66) com as quais eles convivem dioturnamente.

Como é possível verificar, os pesquisadores defendem a inserção das tecnologias digitais como mediadoras dos processos de ensinar e aprender, superando a conotação meramente instrumental que os artefatos tecnológicos assumem na escola. No entanto, precisamos estar atentos ao fato de que a tecnologia por si só não é garantia de um ensino revolucionário, capaz de solucionar dificuldades históricas na educação do nosso país. Como destaca Ribeiro (2017, p.77), "Uma aula em que se faz mais do mesmo, mas na qual se emprega um computador, pode ser apenas uma aula em que se muda a ferramenta, mas não o paradigma".

Isso nos leva a considerar que, olhar para uma experiência como a que apresentamos exige que tenhamos cautela para não nos deixarmos seduzir pela ideia fantasiosa de que a tecnologia é a solução para um ensino de qualidade, ou é a garantia da efetiva aprendizagem. No entanto, precisamos confessar que essa não é uma tarefa fácil, uma vez que o nosso envolvimento com a prática relatada não nos permite um total distanciamento, o que, por certo, contamina a nossa impressão. Mas acreditamos que a experiência vivenciada pelos estagiários e pela supervisora vale a ousadia e o desafio.

\section{A OUSADIA}

A instituição onde a prática docente foi realizada é considerada a maior escola pública da América Latina e uma das mais conceituadas do estado de Santa Catarina. Com mais de 8.000 alunos matriculados, funciona nos períodos matutino, vespertino e noturno e oferece as modalidades de Ensino Fundamental I e II, Ensino Médio Regular, Ensino Médio Inovador e Magistério.

O espaço físico e a organização pedagógica da escola a torna uma referência no estado, tendo salas de aula equipadas com projetores, ar condicionado e armários para uso exclusivo dos alunos. Além disso, há, para uso de alunos e professores, salas de vídeo, biblioteca, aberta das $7 \mathrm{~h}$ às $19 \mathrm{~h}$, laboratórios de química, física, matemática, língua portuguesa e informática, dois auditórios, refeitório, sala de apoio pedagógico, quadras e ginásio de esportes.

A instituição dispõe, ainda, de uma boa estrutura pedagógica da qual fazem parte supervisores e orientadores escolares, além de diretores de ensino. Tal configuração proporciona ao corpo docente uma atualização constante nas discussões sobre o processo de ensino aprendizagem, como é possível evidenciar no Projeto Político Pedagógico, documento cuja versão atualizada data de 2018 e que contempla as mais Revista X, v. 16, n. 6, p. 1908-1924, 2021. 
recentes discussões em curso no âmbito estadual e nacional. A orientação pedagógica encontrada no referido PPP é pautada na Proposta Curricular de Santa Catarina (2014), sendo esta, por sua vez, regida por três fios condutores que se colocam como desafios no campo educacional: i) perspectiva de formação integral, referenciada numa concepção multidimensional de sujeito; ii) concepção de percurso formativo, visando superar o etapismo escolar e a razão fragmentária que ainda predomina na organização curricular; iii) atenção à concepção de diversidade no reconhecimento das diferentes configurações identitárias e das novas modalidades da educação.

Considerando esse contexto, os estagiários criaram certa expectativa com relação à turma onde a prática de estágio seria realizada. No entanto, ao se depararem com o grupo de alunos, já nas primeiras aulas de observação, evidenciaram uma realidade escolar que não se difere muito das demais existentes no nosso país. A Turma 131 se mostrava bastante agitada. Os alunos, em geral, conversavam durante grande parte da aula e mostravam certa resistência para participarem das atividades sugeridas pela professora de Língua Portuguesa. No período das 10 aulas observadas, a dupla de estagiários ficou atenta ao comportamento dos alunos e à forma como eles reagiam às orientações e sugestões de trabalho apresentadas pela professora regente. Perceberam, também, comportamentos e atitudes que os desafiavam, pois as atividades apresentadas pela professora eram diversas e bem orientadas. Além disso, a docente demonstrava preocupação com o aprendizado dos alunos e tinha pleno domínio dos conhecimentos ministrados.

Ainda no decorrer das aulas observadas, outro aspecto chamou a atenção dos professores-estagiários, o envolvimento de parte dos alunos com seus aparelhos celulares. Em todas as aulas, a professora precisava solicitar que silenciassem e guardassem os referidos equipamentos, cujo uso era perceptível, sobretudo, pelos fones de ouvido que alguns alunos portavam. Ainda que seja proibido por lei estadual o uso de telefones celulares em sala de aula nas escolas catarinenses, a proibição, de fato, não acontece. E na Turma 131 não era diferente. Mesmo que a professora, pacientemente, solicitasse aos alunos que não usassem seus telefones, muitos insistiam e demonstravam certa irritação com os pedidos da professora. Diante da realidade observada, os estagiários consideraram necessário pensar em uma forma de envolver os alunos na aula de Língua Portuguesa, sem que fosse necessário criar uma animosidade com eles por causa do celular

Movidos pelas características daquele grupo de alunos e pelo desejo de apresentar a eles uma experiência de ensino que os envolvesse, os professores-estagiários decidiram investir em um projeto de docência que pudesse contemplar o conteúdo da disciplina e o uso de recursos tecnológicos. A dupla apresentou à escola, então, o projeto intitulado 
O ensino de língua portuguesa em tempos de tecnologia digital: entre a ousadia e o desafio. Para tanto, foi considerado o planejamento anual da disciplina, mas sem deixar de lado fatores como a idade dos alunos, suas necessidades e interesses. Nesse sentido, a proposta teve por objetivo aproximar as vivências dos alunos e o conteúdo a ser apreendido, a fim de possibilitar uma compreensão mais ampla das questões linguísticas.

Para a elaboração do trabalho, os professores-estagiários se filiaram a estudos como os de Lúcia Santaella (2013), para quem

\begin{abstract}
À mobilidade física do cidadão cosmopolita foi acrescida a mobilidade virtual das redes. Ambas as mobilidades entrelaçaramse, interconectaram-se e tornaram-se mais agudas pelas ações de uma sobre a outra. A popularização gigantesca das redes sociais do ciberespaço não seria possível sem as facilidades que os equipamentos móveis trouxeram para se ter acesso a elas, a qualquer tempo e lugar. É justamente nesses espaços da hipermobilidade que emergiu o leitor ubíquo, trazendo com ele um perfil cognitivo inédito que nasce do cruzamento e mistura das características do leitor movente com o leitor imersivo. (SANTAELLA, 2013, p. 21).
\end{abstract}

Este novo tipo de leitor, emergido do entrelaçamento da modalidade física com a modalidade virtual das redes digitais, transita habilmente por espaços físicos e virtuais, com familiaridade, desempenho e velocidade nunca antes imaginados, porque tem à disposição um arsenal de recursos tecnológicos: tablets, i-fones, smartphones, notebooks, dentre outros, cujos lançamentos, no mercado consumidor, o tempo de elaboração desse escrito não é capaz de acompanhar.

Assim sendo,

Por meio de pequenos dispositivos, que cabem na palma de nossas mãos, à continuidade do tempo se soma a continuidade do espaço: a informação é acessível de qualquer lugar. Os artefatos móveis evoluíram nessa direção, tornando absolutamente ubíquos e pervasivos o acesso à informação, a comunicação e a aquisição de conhecimento. (SANTAELLA, 2013, p. 23.).

A partir das reflexões aqui colocadas, os professores-estagiários adotaram para a realização do trabalho com a Turma 131 o uso dos dispositivos móveis para pesquisa e, posteriormente, divulgação dos conhecimentos elaborados pelos alunos, no anseio de engajá-los na atividade proposta. $\mathrm{O}$ intuito foi voltar o olhar daqueles jovens para o conhecimento que poderia ser acessado e produzido ali, na sala de aula. Por outro lado, os próprios docentes em formação se mostravam vigilantes no sentido de olhar para as 
práticas dos alunos analisando não somente os sucessos e fracassos gramaticais, mas aquilo que diziam, pensavam e de que forma se expressavam na sociedade.

Dentre as atividades desenvolvidas no período de docência, que envolveu aula expositiva, resolução de exercício, pesquisa, registro fotográfico, seleção de imagens e socialização de resultados, ganha destaque a proposta na qual os alunos, com o uso do celular, pesquisaram, em sites diversos, doze figuras de linguagem estudadas.

Os professores-estagiários vislumbraram aquele momento como uma possiblidade de mobilizar nos estudantes a postura de investigadores e leitores reflexivos. Trazer a pesquisa para a sala de aula foi, ainda, a forma encontrada para evidenciar na prática a concepção de ensino na qual os professores-estagiários acreditam, ou seja, um ensino "como produção de conhecimentos, que resultam, de modo geral, de novas articulações entre conhecimentos disponíveis." (GERALDI, 2010, p. 98). No entanto, já nos gestos iniciais daquela experiência de docência ficou claro que, ainda que houvesse uma orientação cuidadosa sobre como deveria ser realizada a busca, muitos alunos acessavam as informações do primeiro site encontrado, limitando-se, em seguida, a copiar integralmente as informações ali disponíveis.

Diante da realidade que se apresentava, os professores-estagiários entenderam que era preciso uma orientação mais pontual. Decidiram, então, individualmente, explicar aos alunos a necessidade de consultarem fontes mais confiáveis, de se dedicarem à leitura atenta dos conteúdos encontrados, de registrarem no caderno partes dos textos que pudessem ser usados na elaboração de um resumo sobre o conteúdo estudado e de registrarem as fontes consultadas apresentando, posteriormente, as devidas referências.

A partir da leitura dos achados das pesquisas feitas pelos alunos, foi solicitado, primeiramente, que eles definissem um conceito para duas figuras de linguagem, selecionadas previamente e distribuídas aleatoriamente pelos professores-estagiários aos alunos. Após esse primeiro momento, em duplas, eles discutiram os conceitos aos quais chegaram e elaboraram uma definição que contemplasse o conceito que a dupla entendesse ser o mais pertinente. Para finalizar a atividade, todos foram convidados a socializar com o grande grupo a definição elaborada para cada uma das quatro figuras de linguagem pesquisadas.

Evidenciamos, nesse movimento proposto pelos estagiários, uma concepção interacionista/dialógica de linguagem, uma vez que o ensino foi organizado contemplando práticas de uso da língua: fala-escuta, leitura-escrita e análise linguística, eixo principal da atividade. Além disso, os professores-estagiários tiveram por intento proporcionar aos jovens alunos do ensino médio a possiblidade de refletirem sobre a língua, livrando- 
os de uma abordagem que se limita ao "estudo de frases soltas, descontextualizadas e artificiais, criadas com fim, apenas, de fazer o aluno reconhecer as unidades gramaticais, suas nomenclaturas e classificações". (ANTUNES, 2003, p. 123).

Ao que tudo indica, efetivou-se, dessa forma, o objetivo do projeto de docência que tinha por ambição colocar em prática uma proposta que pudesse romper com a visão reducionista do professor como protagonista, visto como o detentor exclusivo dos conteúdos a serem transmitidos. Nesse sentido, a docência em curso se mostrava como possiblidade de romper com práticas tradicionais, que transformam as salas de aula da educação básica do nosso país em espaço vazios de interlocução, restando aos alunos apenas o papel passivo de ouvir, copiar e silenciar.

Finalizada essa primeira parte da atividade sobre figuras de linguagem, os estagiários passaram às próximas orientações para continuidade do trabalho. A proposta, agora, era fazer o registro fotográfico de situações ou cenas do cotidiano escolar que traduzissem em imagens as quatro figuras de linguagem selecionadas. Nesse momento, os alunos passaram a circular pela escola capturando imagens, com o uso do celular. Ao final dessa primeira sessão de fotos, os alunos foram orientados a dar continuidade aos registros fotográficos fora do ambiente escolar. A ideia é que eles fotografassem cenas da cidade ou do bairro onde moravam.

A intenção dos professores-estagiários, ao sugerir o registro fotográfico com o celular, foi trazer para o contexto escolar práticas com as quais os jovens se envolvem cotidianamente, pois evidenciaram, no período de observação das aulas na Turma 131, que considerar essas práticas era "uma forma de dar voz aos estudantes, de propiciar que possam atribuir sentido às aprendizagens escolares sem que tenham que abrir mão de suas referências identitárias.” (BARBOSA, 2018, p. 18). Assim sendo, compreenderam, durante o desenrolar da prática docente, que "Ao invés de aculturar, a escola deve promover percursos que ampliem as referências culturais, explorem as diversidades, até porque muitas das práticas contemporâneas de linguagem são marcadas por hibridismos culturais, outras de suas características. (BARBOSA, 2018, p. 18).

Outro fator de destaque da atividade proposta, na qual o uso de recursos tecnológicos foi intencionalmente incluído, se deve ao fato dela estar em sintonia com o que preconiza as competências 4 e 5 da Base Nacional Comum Curricular, segundo as quais o estudante deve

Utilizar diferentes linguagens - verbal (oral ou visual-motora, como Libras, e escrita), corporal, visual, sonora e digital -, bem como conhecimentos das linguagens artística, matemática e científica, para se expressar e partilhar informações, experiências, ideias e 
sentimentos em diferentes contextos e produzir sentidos que levem ao entendimento mútuo.

Compreender, utilizar e criar tecnologias digitais de informação e comunicação de forma crítica, significativa, reflexiva e ética nas diversas práticas sociais para se comunicar, acessar e disseminar informações, produzir conhecimentos, resolver problemas e exercer protagonismo e autoria na vida pessoal e coletiva. (BRASIL, 2018, p.09)

No encontro seguinte aos registros fotográficos, a aula aconteceu no laboratório de informática. Neste ambiente, os alunos se reuniram, novamente em duplas, e socializaram as fotos feitas por cada um. Após esse primeiro momento, eles foram orientados a selecionar as fotos que correspondessem às figuras de linguagem estudadas e elaborar uma legenda para cada foto. Anteriormente a esta etapa, os professores-estagiários apresentaram ao grupo o perfil do Instagram da turma 131, onde as fotos selecionadas pelas duplas deveriam ser postadas.

Esse momento foi marcado pela empolgação e pelo envolvimento dos alunos. Sem qualquer necessidade de chamar a atenção para atitudes que evidenciavam dispersão, aqueles jovens mostraram intimidade com os recursos tecnológicos necessários para melhorar as fotos, inserir as legendas e compartilhar o trabalho no Instagram da turma. Ademais, merece destaque a criatividade das fotos e legendas.

Após selecionadas as fotos, legendadas e postadas, os alunos foram incentivados a "curtir" e comentar aquelas que consideravam mais criativas. Tendo como objetivo ir além do espaço escolar, os alunos foram orientados a convidar amigos e parentes a "curtir" o perfil da turma. O resultado das publicações surpreendeu os alunos e os levou a evidenciar a amplitude da atividade para além da sala de aula, como se evidencia nas postagens feitas. ${ }^{6}$

\footnotetext{
${ }^{6}$ Outras postagens podem ser vistas no Instagram da Turma 131. 
Imagem 01: Foto representando uma onomatopeia.
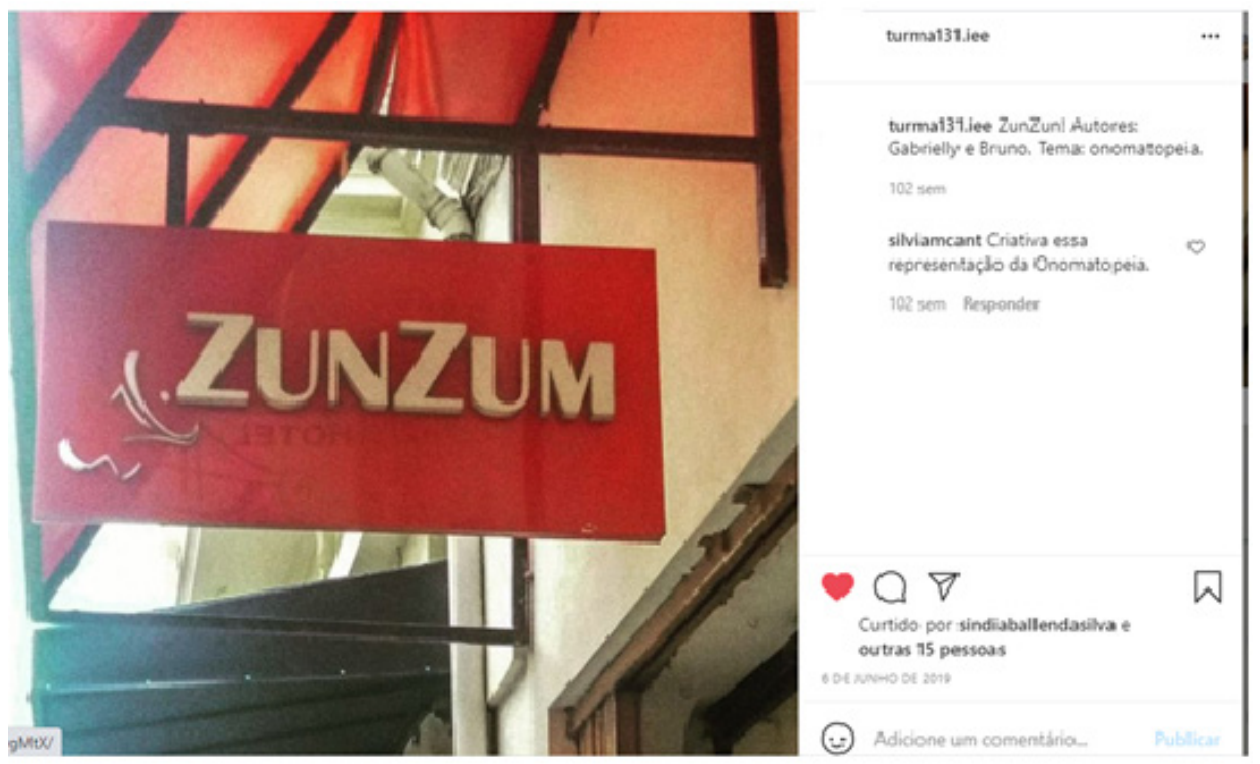

Fonte: Instagram Turma 131.iee ${ }^{7}$

Imagem 02: Foto representando uma personificação.
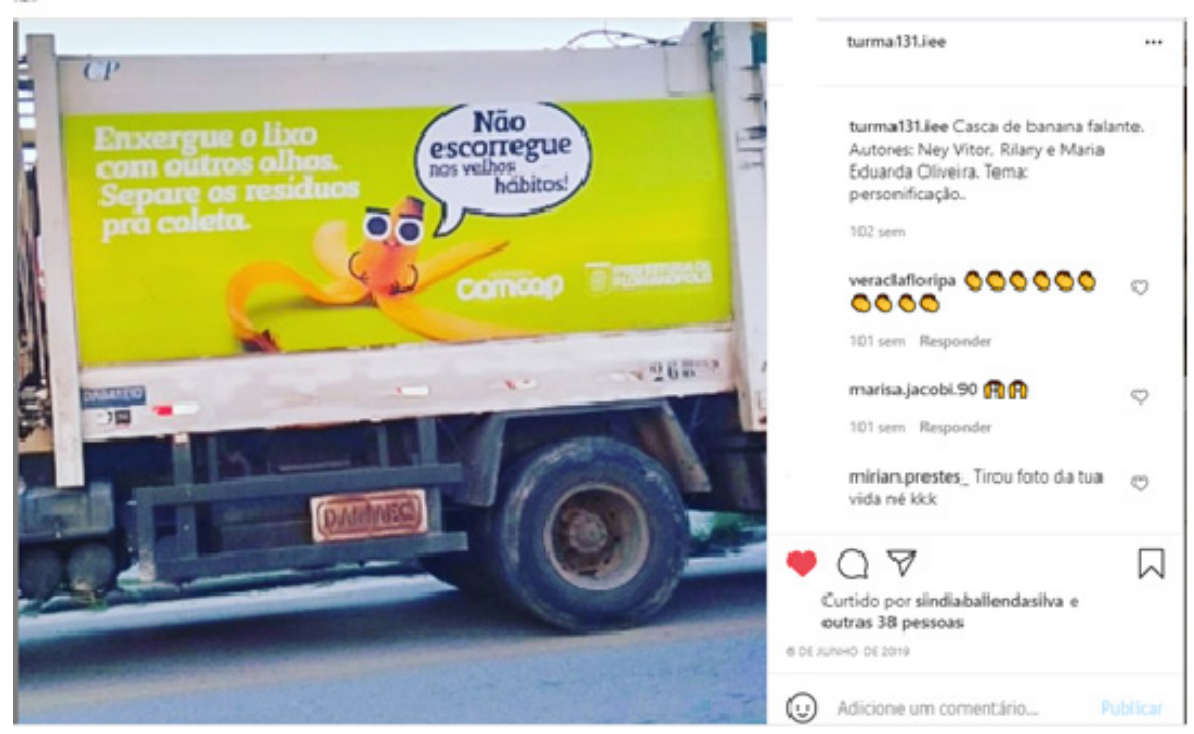

Fonte: Instagram Turma 131.iee ${ }^{8}$

\footnotetext{
${ }^{7}$ Disponível em: https://www.instagram.com/p/ByYyFjDgMtX/

${ }^{8}$ Disponível em: https://www.instagram.com/p/ByYxsbxgb4i/
}

Revista X, v. 16, n. 6, p. 1908-1924, 2021. 
$\mathrm{Na}$ semana seguinte à aula destinada às postagens, os alunos, os professoresestagiários, a professora regente, bem como a supervisora do estágio perceberam a extensão que a dinâmica proposta alcançou, pois foram significativos os números de "curtidas" às postagens no Instagram da turma 131. Diante desse resultado, o conteúdo estudado, ao que tudo indica, teve outro sentido para aqueles jovens alunos do ensino médio.

\section{ENTRE A OUSADIA E O DESAFIO}

Os resultados do percurso realizado pelos alunos da Turma 131 revelaram que o objetivo foi alcançado, uma vez que houve um significativo envolvimento da turma com a atividade e os alunos produziram o conhecimento sobre o tema estudado. Além disso, foi possível evidenciar que a maioria dos alunos demonstrou comprometimento com os colegas, tanto no trabalho em equipe, quanto na apreciação das fotos postadas. Vale ressaltar que a maioria deles revelou muita criatividade no registro das imagens e na elaboração das legendas.

Ao final do trabalho, concluímos que os alunos foram exitosos ao identificar e relacionar com propriedade, nas imagens registradas em contextos diversos, as figuras de linguagem estudadas. No entanto, ao analisar o trabalho como um todo, foi possível entender, também, que o envolvimento da turma resultou muito mais da familiaridade daqueles jovens com o uso das tecnologias que do interesse deles pelo conteúdo estudado. Tal percepção sobre essa realidade se dá, sobretudo, pela necessária insistência dos professores-estagiários para que as pesquisas realizadas na primeira parte do trabalho fossem refeitas algumas vezes, o que exigiu uma orientação atenta para que os alunos da 131 ampliassem as buscas e não se limitassem a copiar o conteúdo do primeiro site encontrado. Nesse sentido, fazê-los entender que o uso da tecnologia deve ir além do caráter meramente instrumental e que, no mundo digital, selecionar informações é indispensável, se mostrou um desafio.

Diante daquela realidade, percebemos que no contato com o universo digital, um dos mais importantes papéis da escola é, por certo, instrumentalizar o aluno para se posicionar criticamente diante do arsenal de informações disponíveis virtualmente. Como assinala Santaella (2013), a oferta desmedida de informações nas redes virtuais não vem acompanhada de orientações que resultem em formas eficientes de seleção, avaliação e utilização eficaz dos conteúdos ali disponíveis.

É importante registrar, também, que o imediatismo gerado pelo uso recorrente da tecnologia parece estar contribuindo para tornar os jovens mais ansiosos, impacientes e, nos parece, com menor capacidade de concentração. Durante a realização de todo o Revista X, v. 16, n. 6, p. 1908-1924, 2021. 
percurso de desenvolvimento do trabalho, foi preciso insistir várias vezes, com todos os grupos, para que registrassem as referências dos sites consultados, identificando a autoria daquela publicação, o que já havia sido enfatizado no início da realização da atividade. Tornou-se necessário, ainda, solicitar que registrassem as legendas ou as revisassem, mais de uma vez. Nesse momento, evidenciamos a falta de preocupação com a correção da linguagem e, por consequência, com uma publicação com erros de registro.

Ao que tudo indica, há um novo desafio para a escola e para os professores, elaborar estratégias de integração entre os processos educativos anteriores e o acesso aos mecanismos de aprendizagem resultantes da inserção dos usuários nos espaços da cibercultura, o que é, de fato, de indiscutível importância. No entanto, encontrar o caminho para essa integração pode ser a oportunidade para tornar o ensino mais rico e próximo dos alunos.

Refletindo sobre o papel dos professores-estagiários naquele processo, tornase importante registrar que, em contato com a realidade escolar, eles perceberam que a atuação em contexto real exigiu deles uma postura de quem "com os alunos (e não para os alunos) pesquisa, observa, levanta hipóteses, analisa, reflete, descobre, aprende, reaprende" (ANTUNES, 2003, p. 108, grifo da autora),

Olhando por essa ótica, podemos afirmar que o estágio se configurou como "possibilidade de os estagiários desenvolverem posturas e habilidades de pesquisador a partir das situações de estágio, elaborando projetos que lhes permitam ao mesmo tempo compreender e problematizar as situações que observam"(PIMENTAE LIMA, 2004,p. 46).

Vista dessa forma, a prática, por certo, se constituiu como mais uma possibilidade de formação de um professor pesquisador, característica indispensável para qualquer docente, uma vez que o conhecimento da realidade escolar e a reflexão sobre esse contexto são subsídios indispensáveis para uma prática que se renova, se atualiza e, por consequência, pode ser mais significativa para todos que nela, ou que com ela, estejam envolvidos.

\section{REFERÊNCIAS}

ANTUNES, Irandé. 2003. Aula de português: encontro e interação. São Paulo, Parábola Editorial, $181 \mathrm{p}$.

BARBOSA, Jaqueline P. As práticas de linguagem contemporâneas e a BNCC. In: Revista na Ponta do Lápis. ano XIV; num. 31; julho de 2018. 
BRASIL. Ministério da Educação e Cultura/Secretaria de Educação Básica. Orientações Curriculares Nacionais (Ensino Médio). Literatura. Ministério da Educação. Secretaria de Educação Média e Tecnológica. Brasília, 2006. Disponível em: http://portal.mec.gov. br/seb/arquivos/pdf/book_volume_01_internet.pdf. Acesso em 19 de novembro de 2019.

. Ministério da Educação. Base Nacional Comum Curricular. Brasília, 2018.

Parâmetros Curriculares Nacionais. (PCNs). Introdução. Ensino Fundamental. Brasília: MEC/SEF, 1998.

GERALDI, João Wanderley. A aula como acontecimento. São Carlos: Pedro \& João Editores, 2010. 208p.

GIL, Antonio Carlos. Como Elaborar Projetos de Pesquisa. $5^{\text {a }}$ ed. São Paulo: Atlas, 2010.

NEITZEL, Adair de Aguiar. A leitura e a escrita em mutação: experiências no meio digital. In: ETD - Educação Temática Digital. Campinas, SP v.18 n.3 p.719-735 jul./set.2016.

OSWALD, Maria Luiza; FERREIRA, Helenice Mirabelli Cassino. Educação e Cibercultura: ler e escrever na contemporaneidade. In: AMARILHA, Marly. (org) Educação e Leitura: novas linguagens, novos leitores. Campinas, SP: Mercado de Letras. Natal, RN: UFRN, Universidade Federal do Rio Grande do Norte, 2012. 136 p.

PIMENTA, Selma Garrido; LIMA, Maria Socorro Lucena. Estágio e docência. 2a ed., São Paulo, Cortez.

RIBEIRO, Ana Elisa. Escrever, hoje: palavra, imagem e tecnologias digitais na educação. 1. ed. São Paulo: Parábola, 2018.

ROJO, Roxane Helena Rodrigues. Letramentos múltiplos, escola e inclusão social. São Paulo: Parábola Editorial, 2009.

Alfabetização e letramentos múltiplos: como alfabetizar letrando? In: BRASIL. Ministério da Educação. Secretaria da Educação Básica. Língua Portuguesa: ensino fundamental, 2010. 200 p.: il. (Coleção Explorando o Ensino. v. 19). 
SANTA CATARINA. Projeto Político Pedagógico. Instituto Estadual de Educação IEE, 2018. Disponível em: http://www.iee.sed.sc.gov.br/a-escola/8-secretaria/27859projeto-politico-pedagogico . Acesso em 26 de janeiro de 2019.

SANTAELLA, Lúcia. Desafios da ubiquidade para a educação. In: Revista Ensino Superior Unicamp. n. 9, abri/jun, 2013. p.19-28. Acesso em 22 de novembro de 2019.

Recebido em: 22 jul. 2021. Aceito em: 01 set. 2021. 